\title{
Exposure as Collected Dose Units
}

National Cancer Institute

\section{Source}

National Cancer Institute. Exposure as Collected Dose Units. NCI Thesaurus. Code C117481.

The unit of measure for the dosage form of the collected exposure. 